\title{
Pro- and anti-inflammatory responses in respiratory syncytial virus bronchiolitis
}

\author{
P.S. McNamara*,\#, B.F. Flanagan ${ }^{\curvearrowleft}$, A.M. Selby ${ }^{+}$, C.A. Hart", R.L. Smyth*
}

Pro- and anti-inflammatory responses in respiratory syncytial virus bronchiolitis. P.S. McNamara, B.F. Flanagan, A.M. Selby, C.A. Hart, R. L. Smyth. C ERS Journals Ltd 2004.

ABSTRACT: Respiratory syncytial virus (RSV) bronchiolitis is an important cause of severe respiratory disease in infants. This study aimed to characterise changes in pulmonary pro- and anti-inflammatory responses in infants with RSV bronchiolitis over the course of the illness.

On the day of intubation (Day 1) and the day of extubation (Day X), nonbronchoscopic bronchoalveolar lavage was performed on term and preterm infants ventilated for RSV bronchiolitis and on control infants on Day 1. Tumour necrosis factor (TNF)- $\alpha$, soluble TNF receptor (sTNFR) and interleukin (IL)-6 messenger ribonucleic acid (mRNA) and protein were measured.

Twenty-four infants, born at term and 23 infants born preterm with RSV bronchiolitis and 10 controls were recruited. TNF- $\alpha$ and IL-6 mRNA and protein in infants with bronchiolitis were greater than the control group on Day 1. In preterm infants, who were ventilated for longer than term infants, TNF- $\alpha$ and IL-6 proteins decreased between Day 1 and Day X. Concentrations of sTNFRs differed between groups on Day 1 , but levels did not change between Day 1 and Day $X$.

Large amounts of tumour necrosis factor- $\alpha$ and interleukin-6 in the respiratory syncytial virus-infected lung suggest important roles for these cytokines in the pathogenesis of respiratory syncytial virus bronchiolitis. The decrease in tumour necrosis factor- $\alpha$ and interleukin- 6 protein in preterm infants may reflect the prolonged clinical course seen in these infants.

Eur Respir J 2004; 23: 106-112.
*Dept of Child Health, University of Liverpool, Institute of Child Health, and ${ }^{+}$Paediatric Intensive Care Unit, Alder Hey Children's Hospital, and Depts of ${ }^{\#}$ Medical Microbiology and Immunology, University of Liverpool, Liverpool, UK.

Correspondence: P.S. McNamara, Institute of Child Health, University of Liverpool, Alder Hey Children's Hospital, Liverpool L12 2AP, UK.

Fax: 441512525456

E-mail: mcnamp@liv.ac.uk

Keywords: Bronchiolitis bronchoalveolar lavage interleukin-6

premature

respiratory syncytial virus tumour necrosis factor

Received: May 12003

Accepted after revision: August 212003

This work was supported by grants from Action Research (Grant Ref. SP3814) and the Charterhouse Charitable Trust, UK
Respiratory syncytial virus (RSV) is a leading cause of lower respiratory tract infection in infants. Each winter, during the annual RSV epidemic, paediatric wards are inundated by large numbers of infants with moderate-to-severe acute bronchiolitis, placing great strains on hospital services [1]. Infants born preterm are predisposed to severe RSV disease and comprise up to two-thirds of infants ventilated with bronchiolitis [2]. They differ from infants born at term in both their disease characteristics and cellular responses to RSV infection [3]. Although it is not clear how RSV causes bronchiolitis or why some normal infants develop severe disease, evidence from both clinical studies and animal models indicates that it has an immunopathological aetiology.

Both tumour necrosis factor (TNF)- $\alpha$ and interleukin (IL)6 are important proinflammatory cytokines with a broad range of biological activities [4]. TNF- $\alpha$ is rapidly produced following either antigen-specific or nonspecific stimulation, and has been designated an early response or alarm cytokine [5]. TNF- $\alpha$ amplifies the immune response by inducing the production of other proinflammatory cytokines, including IL-6 [6]. The actions of TNF- $\alpha$ are produced subsequent to binding to one of two distinct cell surface receptors termed TNF receptor (TNFR)1 and TNFR2 [4]. These membranebound TNFRs are cleaved to produce soluble TNFRs (sTNFR1 and sTNFR2). Soluble receptors compete for TNF binding and function as anti-inflammatory molecules by inhibiting TNF activity [7]. By shedding receptor, susceptible target tissues like the lung may become desensitised to TNF activity.
In vitro studies have shown that alveolar macrophages and respiratory epithelial cells are important sources of both TNF- $\alpha$ and IL-6 in early RSV infection $[8,9]$. Animal studies have emphasised the importance of TNF- $\alpha$ and IL-6 in RSV infection [10-14]. Clinical studies have demonstrated the presence of TNF- $\alpha$ and IL-6 in the airways [15-17] of infants with RSV disease. NOAH et al. [15] showed that elevated TNF- $\alpha$ protein concentrations occurred during acute bronchiolitis and in some patients, persisted for weeks after the acute episode. Others have found correlations between severity of disease and IL-6:TNF- $\alpha$ ratio in nasopharyngeal secretions from infants with RSV bronchiolitis [18].

The nature of the immunological response in the lungs of infants with bronchiolitis is unclear. The hypothesis that over the course of the illness the proinflammatory cytokine response in the lung decreased while the anti-inflammatory response increased was tested. Messenger ribonucleic acid (mRNA) expression and protein concentrations of the proinflammatory cytokines, TNF- $\alpha$ and IL-6, were measured in the lungs of infants ventilated with RSV bronchiolitis on the day of intubation and extubation. The anti-inflammatory response was determined by measuring sTNFR1 and -2 protein concentrations at the same time points. The relationship between cytokine protein concentrations and bronchoalveolar lavage (BAL) cellularity was also examined. Term and preterm infants with RSV bronchiolitis were analysed separately and compared with a control group without respiratory disease. 


\section{Materials and methods}

\section{Study population}

During the 2000-2001 and 2001-2002 RSV seasons, 47 consecutive infants $(24$ term, $\geqslant 37$ weeks gestation and 23 preterm, $<37$ weeks gestation) ventilated for RSV bronchiolitis were recruited to the study. Fourteen of the 23 preterm infants had required ventilation in the neonatal period. Five preterm infants had chronic lung disease of prematurity, and two of these subsequently died during this illness. None of the infants in the study had received passive immunoprophylaxis for RSV bronchiolitis.

Ten control infants were also recruited. The control group comprised term infants of $<1 \mathrm{yr}$ of age intubated but without infective or respiratory disease. Five infants were recruited prior to cardiac surgery and five prior to abdominal surgery.

Clinical characteristics were collected for each infant. They included the Paediatric Index of Mortality (PIM) score, which provides information about the likelihood of death for children in intensive care. The local paediatric research ethics committee approved the study and informed consent was obtained from the parents.

\section{Study design}

In infants ventilated with RSV bronchiolitis, BAL was collected and processed according to recent European Respiratory Society (ERS) guidelines [19]. On the day of intubation (Day 1) and the day of extubation (Day X), TNF- $\alpha$ and IL-6 mRNA expression and protein concentration in BAL were compared, as well as sTNFR protein concentrations. One BAL sample was collected from each infant in the control group on Day 1. Term and preterm infants with RSV bronchiolitis were analysed separately and compared with the control group.

\section{Sample preparation and ribonucleic acid isolation}

Standard techniques were used to assess cell concentration and differential cell counts. BAL fluid was centrifuged and the supernatant removed and stored at $-80^{\circ} \mathrm{C}$. The cell pellet was resuspended in Trizol (Gibco, Basingstoke, UK) with RNA isolated according to the manufacturer's instructions. The RNA was dried and resuspended in hybridisation buffer (BD Biosciences, Oxford, UK) and stored at $-80^{\circ} \mathrm{C}$ until analysis.

\section{Ribonuclease protection assay}

The ribonuclease (RNase) protection assay was performed according to the manufacturer's instructions (BD Biosciences) as described previously [20] using a custom-made probe set containing TNF- $\alpha$, IL-6, and glyceraldehyde-3-phosphate dehydrogenase (GAPDH). Briefly, probe solutions were hybridised overnight to patient RNA samples taken on Day 1 and Day X. Following RNase digestion, the samples underwent phenol extraction before precipitation in ethanol. Each sample was loaded on a polyacrylamide gel. The gels were exposed to autoradiography film and densitometric analysis of TNF- $\alpha$ and IL- 6 bands carried out using the "Image" programme (National Institute for Health, Washington, VA, USA). Cytokine mRNA in each sample was expressed relative to the level of GAPDH control transcript.

\section{Enzyme-linked immunosorbent assay}

TNF- $\alpha$, IL-6, sTNFR 1 and sTNFR2 protein concentration in BAL fluid supernatant was quantified using commercially available enzyme-linked immunosorbent assays (ELISAs; R\&D Systems Europe, Abingdon, UK) on Day 1 and Day X. The lower detection limits of these assays were TNF- $\alpha 0.18 \mathrm{pg}$. $\mathrm{mL}^{-1}, \mathrm{IL}-60.18 \mathrm{pg} \cdot \mathrm{mL}^{-1}$, sTNFR1 $3.0 \mathrm{pg} \cdot \mathrm{mL}^{-1}$, and sTNFR2 $1.0 \mathrm{pg} \cdot \mathrm{mL}^{-1}$.

\section{Statistics}

Normally distributed data were expressed as mean \pm SD. Differences between Day 1 and Day X were examined using the paired samples t-test while differences between groups were examined using an unpaired two-sample t-test.

Nonparametric data were expressed as median (interquartile range) with differences between Day 1 and Day $\mathrm{X}$ examined using the Wilcoxon-matched pairs test, and differences between groups examined using the Mann-Whitney U-test. The relationship between cytokine/cytokine-receptor protein concentrations and total cell concentration was examined using scatter plots and Pearson correlation coefficients (r). All statistical tests were two-tailed and a p-value of $\leqslant 0.05$ was taken as statistically significant.

\section{Results}

\section{Subjects}

Overall, 90 BAL samples were collected from infants with bronchiolitis and 10 BAL samples from control infants. The characteristics of the patients and BAL are presented in table 1. The PIM score was similar in all infants with bronchiolitis (term $0.124 \pm 0.07$, preterm $0.147 \pm 0.08$ ). The proportion of preterm infants requiring intubation for apnoea was higher than for term infants (preterm 12 of 23, term seven of 24). There were no significant differences between term and preterm infants in the amount of respiratory support required either on the Day 1 or Day X (data not shown). Preterm infants were ventilated for significantly longer than term infants with bronchiolitis (preterm 151 (130) h, term 96 (32) h; p<0.01).

BAL cellularity was highest in term infants with bronchiolitis and decreased between the Day 1 and Day X in both term and preterm infants with bronchiolitis. The predominant cellular component of BAL in these infants comprised neutrophils (median $86 \%$ ), alveolar macrophages $(8.5 \%)$ and lymphocytes $(5 \%$; table 1$)$.

\section{Tumour necrosis factor- $\alpha$ and interleukin- 6 messenger ribonucleic acid expression}

On Day 1, both TNF- $\alpha$ and IL-6 mRNA expression relative to GAPDH in term and preterm infants with bronchiolitis were significantly greater than in the control group $(\mathrm{p}<0.01$; fig. 1). There were no significant differences in TNF$\alpha$ or IL- 6 mRNA expression between term and preterm infants on Day 1. TNF- $\alpha$ and IL- 6 mRNA expression did not decrease between the Day 1 and Day $\mathrm{X}$ in either term or preterm infants with bronchiolitis.

\section{Tumour necrosis factor- $\alpha$ and interleukin-6 proteins}

On Day 1, TNF- $\alpha$ protein concentrations were significantly greater in term $(25.9(98.4) \mathrm{pg} \cdot \mathrm{mL})$ than preterm $(8.5(48.4)$ 
Table 1.-Clinical characteristics of term and preterm infants ventilated with respiratory syncytial virus bronchiolitis

\begin{tabular}{|c|c|c|c|}
\hline & Term & Preterm & Control \\
\hline \multicolumn{4}{|l|}{ Clinical characteristics } \\
\hline $\mathrm{F} / \mathrm{M} \mathrm{n}$ & $17 / 7$ & $11 / 12$ & $8 / 2$ \\
\hline Admission weight $\mathrm{kg}$ & $4.2 \pm 1.2$ & $3.5 \pm 1.3$ & $3.3 \pm 0.8$ \\
\hline Gestation at birth weeks & $38.7 \pm 1.6$ & $30.1 \pm 3.6^{* *}$ & $38.4 \pm 1.4$ \\
\hline Age on admission weeks & $6.1 \pm 4.9$ & $16.0 \pm 14.7 * *$ & $1.0 \pm 2.5$ \\
\hline Corrected age weeks & $4.8 \pm 5.5$ & $5.6 \pm 13.1$ & $0.4 \pm 3.2$ \\
\hline Time from disease onset to intubation days & $5.7 \pm 2.9$ & $5.4 \pm 2.2$ & N/A \\
\hline Time ventilated $\mathrm{h}$ & $96(32)$ & $151(130)^{\#}$ & N/A \\
\hline Patients presenting with apnoea/total $\mathrm{n}$ & $7 / 24$ & $12 / 23$ & N/A \\
\hline PIM score & $0.124 \pm 0.07$ & $0.147 \pm 0.08$ & N/A \\
\hline \multicolumn{4}{|l|}{ BAL characteristics } \\
\hline Total cell concentration on day $1 \times 10^{6}$ cells $\cdot \mathrm{mL}^{-1}$ & $4.40(4.38)$ & $2.46(5.69)^{* *}$ & $0.56(0.36)$ \\
\hline Total cell concentration on day $\mathrm{X} \times 10^{6}$ cells $\cdot \mathrm{mL}^{-1}$ & $1.28(1.26)$ & $0.67(0.62)^{\#}$ & N/A \\
\hline Neutrophils \% & $86.0(13.3)^{*}$ & $80.0(16.0)$ & $52.3(27.7)$ \\
\hline Alveolar macrophages $\%$ & $8.5(6.0)$ & $11.0(14.0)$ & $32.7(23.3)$ \\
\hline Lymphocytes $\%$ & $5.0(4.3)$ & $7.0(7.0)$ & $11.0(13.0)$ \\
\hline
\end{tabular}

Data are presented as mean \pm SD or median (interquartile range) unless otherwise stated. The table shows characteristics of bronchoalveolar lavage (BAL) samples in the three groups. F: female; M: male; N/A: not applicable; PIM: Paediatric Index of Mortality. *: p $<0.05$ between all three groups; **: $\mathrm{p}<0.01$ compared with term and control infants; ${ }^{\#}: \mathrm{p}<0.01$ compared with term infants. Total cell concentration also decreased between day 1 and day $\mathrm{X}$ in both term and preterm infants with bronchiolitis $(\mathrm{p}<0.01)$.
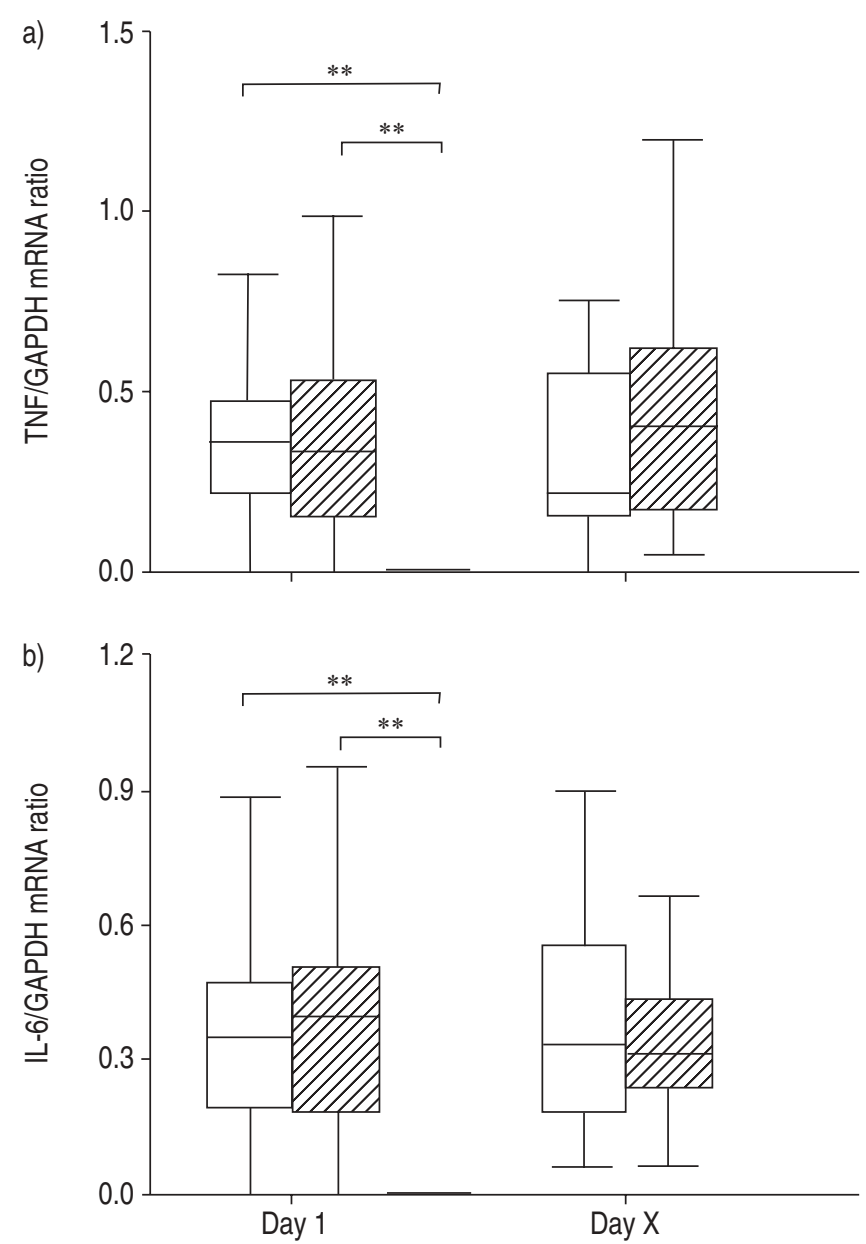

Fig. 1.-Box and whisker plots showing median (horizontal band), interquartile range (top and bottom of the box) and range (whiskers) for a) tumour necrosis factor (TNF)- $\alpha$ and b) interleukin (IL)-6 messenger ribonucleic acid (mRNA) expression in bronchoalveolar lavage samples taken on the day of intubation (Day 1) and the day of extubation (Day X) from infants with respiratory syncytial virus bronchiolitis and on Day 1 in control infants. GAPDH: glyceraldehyde-3-phosphate dehydrogenase. $\mathrm{n}$ ranges $10-19$. $\square$ : term; $\mathbb{Z}$ : preterm; $\mathbf{0}$ : control. ${ }^{* *}$ : $\mathrm{p}<0.01$. $\left.\mathrm{pg} \cdot \mathrm{mL}^{-1} ; \mathrm{p}<0.05\right)$ infants with bronchiolitis and the control group (2.0 (5.2) $\mathrm{pg} \cdot \mathrm{mL}^{-1}, \mathrm{p}<0.01$; fig. $\left.2 \mathrm{a}\right)$. TNF- $\alpha$ protein decreased between Day 1 and Day $X$ in preterm $(p<0.01)$ but remained raised in term infants.

On Day 1, IL-6 protein concentration was significantly greater in term $\left(295.4(484.6) \mathrm{pg} \cdot \mathrm{mL}^{-1}\right)$ than preterm $(189.5$ (285.4) $\left.\mathrm{pg} \cdot \mathrm{mL}^{-1} ; \mathrm{p}<0.05\right)$ infants with bronchiolitis and the control group (28.8 (126.9) $\mathrm{pg} \cdot \mathrm{mL}^{-1}, \mathrm{p}<0.01$; fig. 2b). IL-6 protein decreased between Day 1 and Day $X$ in preterm infants $(p<0.05)$ but remained raised in term infants. There were no significant differences in $\mathrm{TNF}-\alpha$ or IL-6 protein concentrations between preterm infants and control infants on Day 1. On Day 1, there were significant correlations between TNF- $\alpha$ protein and total BAL cellularity in preterm $(\mathrm{p}<0.001)$ but not term $(\mathrm{p}=0.065)$ infants (fig. 3a). In contrast, IL-6 protein correlated with BAL cellularity in term $(\mathrm{p}<$ 0.001 ) but not preterm ( $\mathrm{p}=0.984)$ infants (fig. $3 \mathrm{~b}$ ).

\section{Tumour necrosis factor-receptor proteins}

On Day 1, in term infants with bronchiolitis, sTNFR1 protein concentration was significantly greater than in preterm infants (term $797.9(1,901.0) \mathrm{pg} \cdot \mathrm{mL}^{-1}$, preterm $415.8(574.3)$ $\left.\mathrm{pg} \cdot \mathrm{mL}^{-1} ; \mathrm{p}<0.05\right)$ and similar to controls $(970.3(1,445.5)$ $\mathrm{pg} \cdot \mathrm{mL}^{-1}$; fig. $\left.4 \mathrm{a}\right)$. sTNFR1 did not decrease between Days 1 and $\mathrm{X}$ in either term or preterm infants.

sTNFR2 did not decrease between Days 1 and $X$ in either term or preterm infants. On Day 1, sTNFR2 protein concentration in term infants $\left(1,289.5(2,289.5) \mathrm{pg} \cdot \mathrm{mL}^{-1}\right)$ with bronchiolitis was significantly greater than preterm infants (368.4 (473.7) $\left.\mathrm{pg} \cdot \mathrm{mL}^{-1} ; \mathrm{p}<0.05\right)$ and controls (502.3 (498.4) $\mathrm{pg} \cdot \mathrm{mL}^{-1}, \mathrm{p}<0.05$; fig. $\left.4 \mathrm{~b}\right)$. There were no significant differences in either sTNFR1 or sTNFR2 between preterm infants and control infants on Day 1.

In term infants, sTNFR1 and sTNFR2 correlated with BAL cellularity on Day $1(\mathrm{p} \leqslant 0.001)$ (figs. $3 \mathrm{c}$ and $3 \mathrm{~d})$. In preterm infants, sTNFR1 $(\mathrm{p}<0.001)$ but not sTNFR2 $(\mathrm{p}=0.652)$ correlated with BAL cellularity.

\section{Discussion}

To the best of the authors' knowledge, this is the first study to quantify both pro- and anti-inflammatory cytokine 

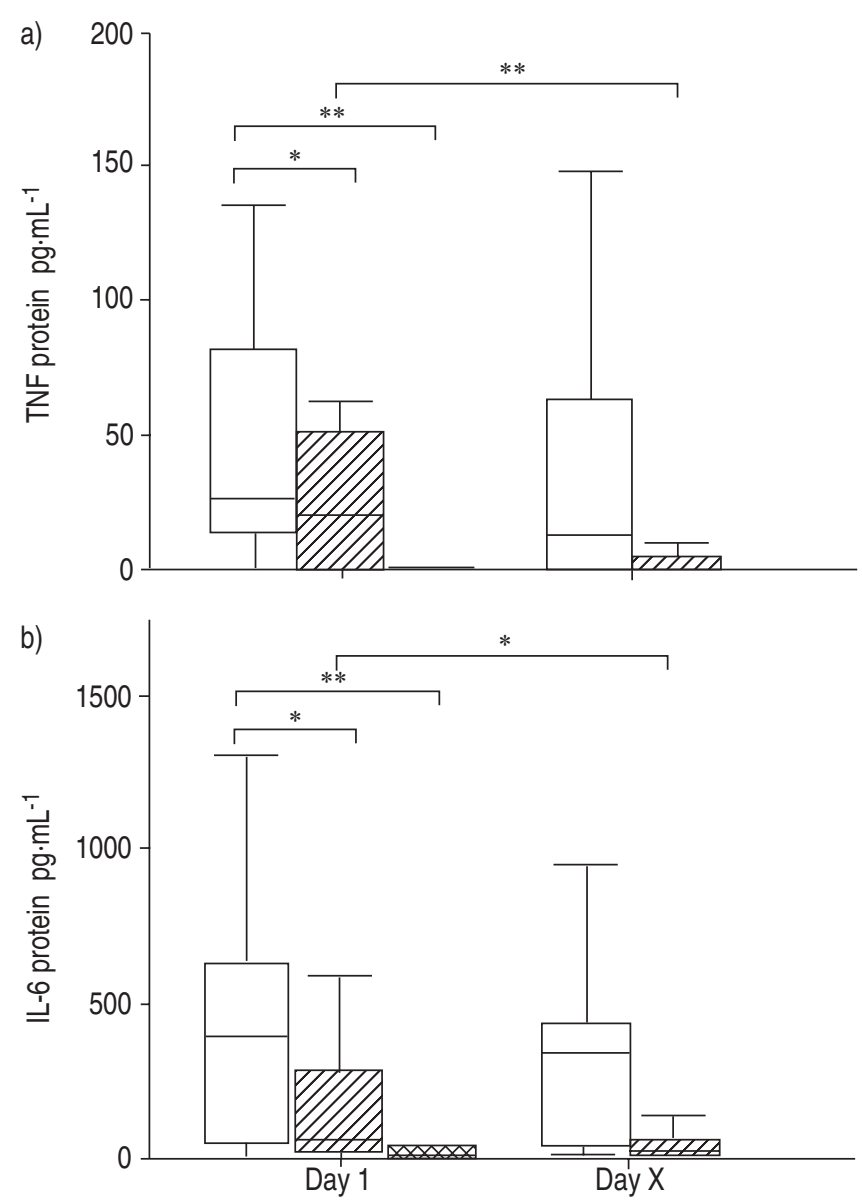

Fig. 2.-Box and whisker plots showing median (horizontal band), interquartile range (top and bottom of the box) and range (whiskers) for a) tumour necrosis factor (TNF)- $\alpha$ and b) interleukin (IL)-6 protein concentrations in bronchoalveolar lavage samples taken on Day 1 and Day X from infants with bronchiolitis and on Day 1 in control infants. n ranges $10-25$. $\square$ : term; $\mathbb{Z}$ : preterm; $\mathbf{D}$ control. *: $\mathrm{p}<0.05 ; * *: \mathrm{p}<0.01$.

responses in the lower airways of a large cohort of infants ventilated with RSV bronchiolitis over time. It is also the first study to compare these responses to a control group, ventilated but without respiratory disease. Term infants with bronchiolitis were ventilated for a median of 4 days, and in these infants it has been shown that TNF- $\alpha$ and IL-6 proteins were raised compared with controls on intubation and continued to be raised on extubation. Preterm infants were ventilated for a median of 6 days, and both TNF- $\alpha$ and IL-6 proteins decreased between Day 1 and Day X. Proinflammatory cytokine mRNA expression in the lung remained elevated in both term and preterm infants with bronchiolitis on Day X. sTNFR protein concentrations did not change between Day 1 and Day $X$ in both groups. In term infants, there were strong correlations between cytokine/ cytokine receptors and BAL cellularity. These correlations were not as strong in preterm infants.

A number of studies have demonstrated the presence of TNF- $\alpha$ and IL- 6 in the upper airways $[15,17]$ and the lower airways [11] of infants with RSV disease. MATSUDA et al. [17] detected TNF- $\alpha$ and IL- 6 protein in $67 \%$ and $100 \%$, respectively, of nasopharyngeal secretions from infants with RSV bronchiolitis at some point during the course the illness. TNF- $\alpha$ protein was shown to peak in the first 5 days after the onset of the illness and then decrease in convalescence [17]. Another study of nasal cytokine production in acute viral upper respiratory tract infection showed that elevated TNF- $\alpha$ and IL- 6 protein concentrations occurred during the acute episode, and in some patients, elevated TNF- $\alpha$ levels persisted for 2-3 weeks [10]. HoRNSLETH et al. [18] found that disease severity correlated with IL-6:TNF- $\alpha$ ratio in nasopharyngeal secretions from infants with RSV bronchiolitis.

More evidence supporting the role of TNF- $\alpha$ in RSV disease has come from animal models. RONTVED et al. [14] experimentally infected calves with bovine RSV and showed that BAL TNF- $\alpha$ protein concentrations peak 7 days postinoculation and then start to decline. In cotton rats after primary RSV infection, pulmonary TNF- $\alpha$ mRNA expression peaks 1 day after inoculation and then decreases gradually but continues to be expressed up to 21 days postinoculation [10]. In the same study, TNF- $\alpha$ mRNA expression peaked later (day 5) after secondary RSV infection and remained elevated for longer. In the present study, given that the incubation period for RSV is 5-8 days [21], and the mean time from onset of respiratory symptoms to intubation in both term and preterm infants was $\sim 5$ days, these high TNF- $\alpha$ protein concentrations are being observed $\sim 10-13$ days following initial infection.

Studies in mice have investigated whether lung damage due to RSV infection is due to overproduction of TNF- $\alpha$. In a study by NEUZIL et al. [13], of primary RSV infection in mice, treatment with an anti-TNF- $\alpha$ antibody was associated with marginally greater weight loss and slower recovery than in mice not treated in this way, suggesting that TNF- $\alpha$ is protective in RSV disease. In another study, HuSSELL et al. [12] investigated the role of $\mathrm{TNF}-\alpha$ in mice previously sensitised to either the RSV G or F protein. Treatment with an anti-TNF antibody during subsequent RSV infection in these mice was associated with decreased weight loss and illness severity. This implied that TNF- $\alpha$ depletion was protective in RSV disease and led to the suggestion that anti-TNF treatments may be a possible therapeutic intervention in human RSV infection [12]. These studies suggest that $\mathrm{TNF}-\alpha$ may have a different role in primary compared with secondary RSV infection. It is not possible to say from the present research whether TNF- $\alpha$ and IL-6 play a beneficial role in RSV bronchiolitis or not. However, a recent case report should sound a cautionary note regarding the possible use of TNF inhibitors in RSV disease [22]. This described a female aged 54 yrs who developed severe parainfluenza pneumonia whilst being treated with a TNF inhibitor. The authors noted that a number of the etanercept clinical trials demonstrated a trend of increased respiratory infections in the treatment groups. In the present study, proinflammatory cytokine mRNA and protein have been measured and significant quantities of both have been shown to be present within the RSV-infected lower airway. RNase protection assays were used to analyse TNF- $\alpha$ and IL- 6 mRNA expression relative to a housekeeping gene. While TNF- $\alpha$ :GAPDH or IL-6:GAPDH ratios remain raised over the course of ventilation, the actual amount of proinflammatory cytokine mRNA within BAL probably decreased over this time. This is because the cellularity and therefore the number of cells capable of expressing TNF$\alpha$ and/or IL-6 in the BAL samples decreased over the course of ventilation.

Protein analysis in BAL is an area of controversy at the moment because epithelial lining fluid cannot be reliably measured using the same reference substances in both healthy and disease states [19]. Recent ERS guidelines were followed [19], which suggest that levels of solute in BAL are reported as concentration per millilitre lavage fluid returned. Each BAL was performed systematically by one operator. While variations in the quality of the BAL samples were possible, the observed differences within and between infant groups in protein concentration are probably an accurate reflection of 

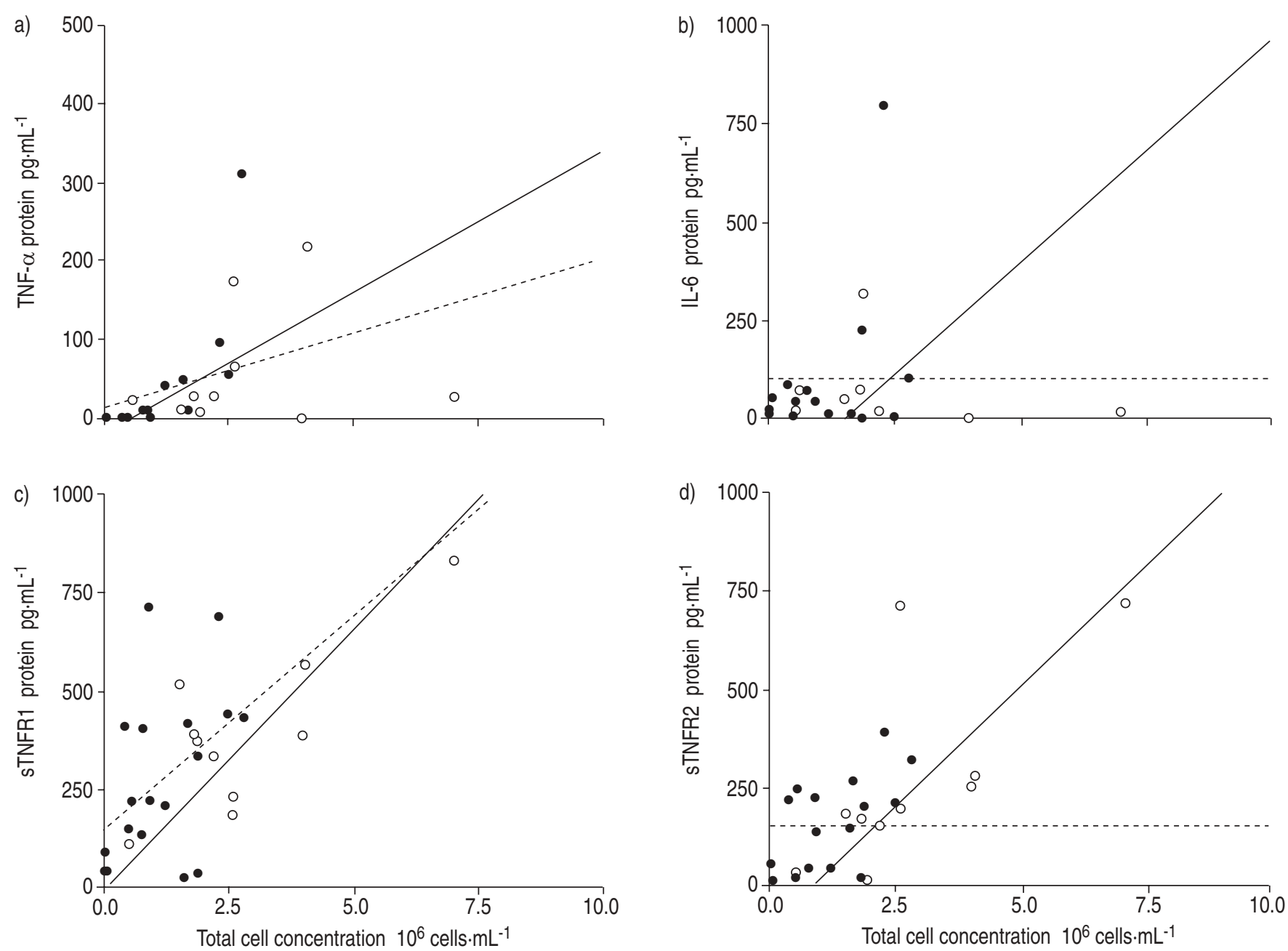

Fig. 3. - Scatter plots showing a) tumour necrosis factor (TNF)- $\alpha$, b) interleukin (IL)-6, c) soluble TNF-receptor (sTNFR) 1 and d) sTNFR2 protein concentrations against total cell concentrations in bronchoalveolar lavage samples taken on Day 1 from term $(\bullet,--)$ and preterm $(\bigcirc$, -) infants with respiratory syncytial virus bronchiolitis. a) Preterm $r^{2}=0.7302, p<0.001$; term $\left.r^{2}=0.2552, p=0.065 ; b\right) p r e t e r m r^{2}=0.0000, p=0.984$; term $\mathrm{r}^{2}=0.8165, \mathrm{p}<0.001$; c) preterm $\mathrm{r}^{2}=0.9132, \mathrm{p}<0.001$; term $\mathrm{r}^{2}=0.7326, \mathrm{p}<0.001$; and d) preterm $\mathrm{r}^{2}=0.0130, \mathrm{p}=0.652 ;$ term $\mathrm{r}^{2}=0.6868, \mathrm{p}=0.001$.

the amount of proinflammatory protein within the RSVinfected airway.

TNF- $\alpha$ and IL- 6 protein concentrations fell in preterm but not term infants with bronchiolitis between Day 1 and $\mathrm{X}$ despite similarities in both corrected age and weight on admission. There are a number of reasons for this observation. Preterm infants were ventilated for significantly longer than term infants (preterm $151 \mathrm{~h}$, term $96 \mathrm{~h} ; \mathrm{p}<0.01$ ). On Day $\mathrm{X}$, this longer period of ventilation may simply have allowed greater opportunity for the inflammatory response to diminish in the preterm RSV-infected lung compared with the term lung. Another possible reason for this difference may be the underlying lung pathology in preterm infants. Term infants may have sufficient physiological reserve to manage without artificial respiratory support in spite of a persistent inflammatory response in their lungs. Preterm infants, with potentially narrowed and fibrotic airways, may require ventilation for longer until the inflammatory response has abated. However, the proinflammatory response also differed in term and preterm infants on Day 1. It is suggested that preterm infants require a less vigorous proinflammatory response to cause the critical airways obstruction necessary for intubation and ventilation.

The high amounts of TNF- $\alpha$ and IL- 6 mRNA indicate that BAL cells from infants with RSV bronchiolitis produce both TNF- $\alpha$ and IL-6. This suggests that temporarily, at least in preterm infants, much of the proinflammatory protein in BAL derives from inflammatory cells recruited into the airway rather than cells lining the airway. However, while there were correlations between BAL cellularity and TNF- $\alpha$ protein and sTNFR1 protein for both term and preterm infants, for IL-6 and sTNFR2, a significant correlation was only found for term infants.

The exact role of the two membrane-bound TNF receptors in mediating the effect of TNF- $\alpha$ is still being debated. TNFR 1 is the major mediator of TNF- $\alpha$ biological functions including apoptosis and chemotaxis. However, TNFR2 can also mediate these activities although through different intracellular signalling pathways. sTNFRs are the shed extracellular domains of membrane-bound TNF receptors and probably have anti-inflammatory properties [6]. Both sTNFR1 and sTNFR2 can bind TNF- $\alpha$ and may "mop up" unbound TNF- $\alpha$, protecting other cells from its effects and localising the inflammatory response [23, 24]. Increased levels of sTNFRs are found in inflammatory or infectious diseases characterised by chronic immune activation such as acquired immune deficiency syndrome [25]. However, very few studies have examined TNF receptors in RSV infection [23]. Disease severity in infants with RSV bronchiolitis correlates with STNFR1/RANTES (regulated on activation, T-cell expressed and secreted) ratios [26]. In vitro work has shown that RSVinfected peripheral blood mononuclear cells shed sTNFR1, 

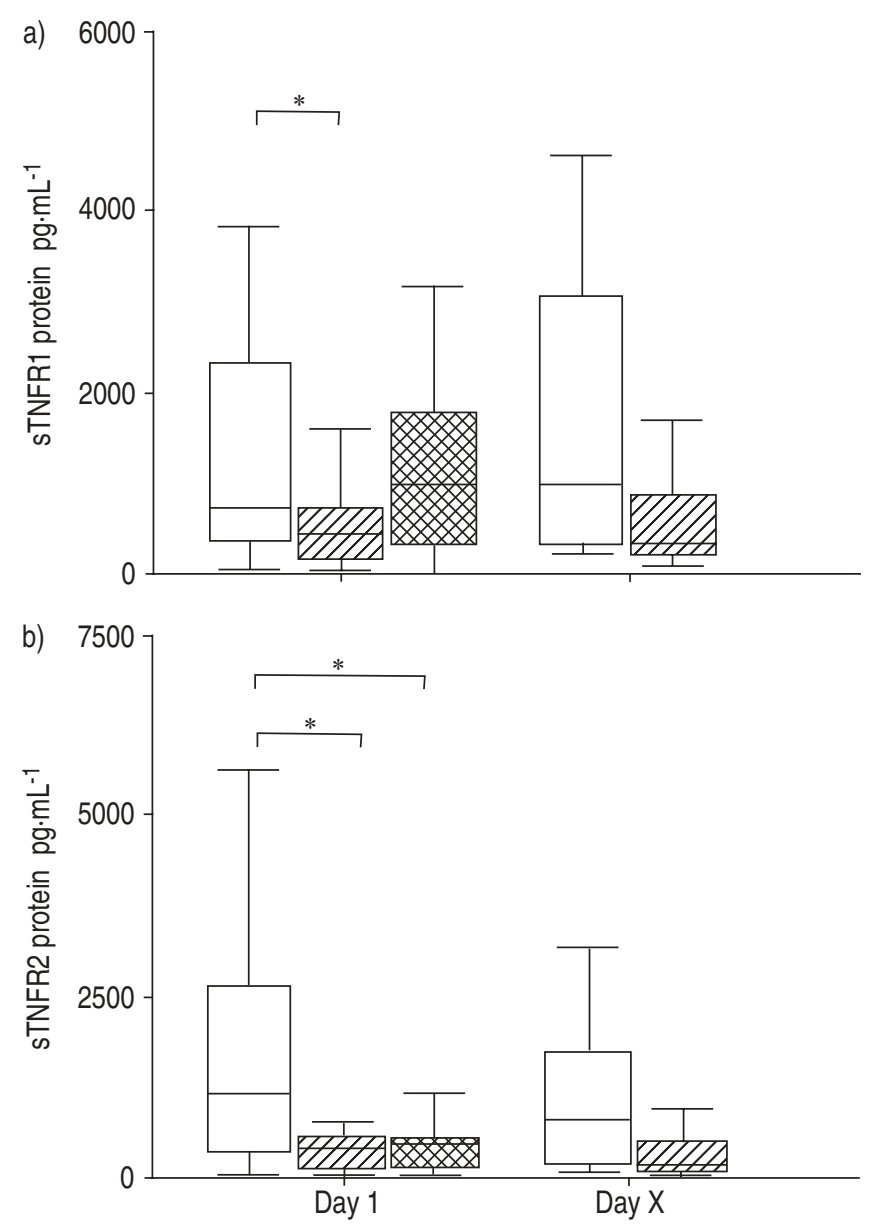

Fig. 4. - Box and whisker plots showing median (horizontal band), interquartile range (top and bottom of the box) and range (whiskers) for a) soluble tumour necrosis factor-receptor (sTNFR)1 and b) sTNFR2 protein concentrations in bronchoalveolar lavage samples taken on Day 1 and Day X in infants with bronchiolitis and on Day 1 in control infants. n ranges $10-24$. $\square$ : term; $\mathbb{Z}$ : preterm; $\mathbf{B}$ : control. $*: \mathrm{p}<0.05$.

while membrane-bound expression of both receptors remains unchanged [27]. Interestingly, there is structural homology between part of the RSV attachment protein $\mathrm{G}$ and part of the sTNFR1, which may interfere with the actions of TNF- $\alpha$ [28].

The authors hypothesised that BAL concentrations of these soluble receptors, with their anti-inflammatory effects, would increase over the course of the illness as the infants clinical condition improved. However, while there were differences between the three study groups in soluble receptor concentrations on Day 1, in those infants with bronchiolitis, concentrations remained remarkably constant over the course of the illness. Soluble receptor concentrations appeared to correlate well with BAL cellularity and it may be that BAL concentrations of these proteins merely reflect cellular recruitment into the airway. The potential anti-inflammatory role of these proteins in the RSV-infected lung is difficult to discern from the present results.

In summary, tumour necrosis factor- $\alpha$ and interleukin-6 messenger ribonucleic acid and protein are present in the lower airways in infants with respiratory syncytial virus bronchiolitis. The presence of tumour necrosis factor- $\alpha$ and interleukin-6 messenger ribonucleic acid and protein in the lungs of infants with bronchiolitis suggest important roles for these cytokines in the immunopathogenesis of severe respiratory syncytial virus bronchiolitis. Soluble tumour necrosis factor receptor concentrations vary between patient groups and at different time points after intubation. Further work is required to establish the role of these soluble receptors in respiratory syncytial virus disease and to investigate the relationship between the soluble and membrane-bound versions of the receptor.

Acknowledgements. The authors would like to thank P.J. Openshaw for helpful comments during the preparation of this manuscript.

\section{References}

1. Shay DK, Holman RC, Newman RD, Liu LL, Stout JW, Anderson LJ. Bronchiolitis-associated hospitalizations among US children, 1980-1996. JAMA 1999; 282: 14401446.

2. Gavin R, Anderson B, Percival T. Management of severe bronchiolitis: indications for ventilator support. NZ Med J 1996; 109: 137-139.

3. McNamara PS, Ritson PC, Selby AM, Hart CA, Smyth RL. Bronchoalveolar lavage cellularity in infants with severe respiratory syncytial virus bronchiolitis. Arch Dis Child 2003; 88: 922-926.

4. Bazzoni F, Beutler B. The tumor necrosis factor ligand and receptor families. N Engl J Med 1996; 334: 1717-1725.

5. Zhang P, Summer WR, Bagby GJ, Nelson S. Innate immunity and pulmonary host defense. Immunol Rev 2000; 173: 39-51.

6. MacEwan DJ. TNF receptor subtype signalling: differences and cellular consequences. Cell Signal 2002; 14: 477-492.

7. Opal SM, DePalo VA. Anti-inflammatory cytokines. Chest 2000; 117: 1162-1172.

8. Franke-Ullmann G, Pfortner C, Walter P, et al. Alteration of pulmonary macrophage function by respiratory syncytial virus infection in vitro. J Immunol 1995; 154: 268-280.

9. Franke G, Freihorst J, Steinmuller C, Verhagen W, Hockertz $\mathrm{S}$, Lohmann-Matthes ML. Interaction of alveolar macrophages and respiratory syncytial virus. J Immunol Methods 1994; 174: 173-184.

10. Noah TL, Henderson FW, Wortman IA, et al. Nasal cytokine production in viral acute upper respiratory infection of childhood. J Infect Dis 1995; 171: 584-592.

11. Midulla F, Villani A, Panuska JR, et al. Respiratory syncytial virus lung infection in infants: immunoregulatory role of infected alveolar macrophages. J Infect Dis 1993; 168: 1515-1519.

12. Blanco JC, Richardson JY, Darnell ME, et al. Cytokine and chemokine gene expression after primary and secondary respiratory syncytial virus infection in cotton rats. $J$ Infect Dis 2002; 185: 1780-1785.

13. Hayes PJ, Scott R, Wheeler J. In vivo production of tumour necrosis factor-alpha and interleukin-6 in BALB/c mice inoculated intranasally with a high dose of respiratory syncytial virus. J Med Virol 1994; 42: 323-329.

14. Hussell T, Pennycook A, Openshaw PJ. Inhibition of tumor necrosis factor reduces the severity of virus-specific lung immunopathology. Eur J Immunol 2001; 31: 2566-2573.

15. Neuzil KM, Tang YW, Graham BS. Protective role of TNFalpha in respiratory syncytial virus infection in vitro and in vivo. Am J Med Sci 1996; 311: 201-204.

16. Rontved CM, Tjornehoj $\mathrm{K}$, Viuff $\mathrm{B}$, et al. Increased pulmonary secretion of tumor necrosis factor-alpha in calves experimentally infected with bovine respiratory syncytial virus. Vet Immunol Immunopathol 2000; 76: 199214.

17. Matsuda K, Tsutsumi H, Okamoto Y, Chiba C. Development of interleukin 6 and tumor necrosis factor alpha activity in nasopharyngeal secretions of infants and children 
during infection with respiratory syncytial virus. Clin Diagn Lab Immunol 1995; 2: 322-324.

18. Hornsleth A, Klug B, Nir M, et al. Severity of respiratory syncytial virus disease related to type and genotype of virus and to cytokine values in nasopharyngeal secretions. Pediatr Infect Dis J 1998; 17: 1114-1121.

19. de Blic J, Midulla F, Barbato A, et al. Bronchoalveolar lavage in children. ERS Task Force on bronchoalveolar lavage in children. European Respiratory Society. Eur Respir $J$ 2000; 15: 217-231.

20. Betts CJ, Dearman RJ, Flanagan BF, Kimber I. Temporal changes in cytokine gene expression profiles induced in mice by trimellitic anhydride. Toxicol Lett 2002; 136: 121-132.

21. Hall CB. Respiratory syncytial virus. In: Feigin RD, Cherry JD, eds. Textbook of Paediatric Infectious Diseases. Philadelphia, W.B. Saunders, 1998; pp. 2084-2111.

22. Smith D, Letendre S. Viral pneumonia as a serious complication of etanercept therapy. Ann Intern Med 2002; 136: 174.

23. Herbein $\mathrm{G}, \mathrm{O}^{\prime}$ Brien WA. Tumor necrosis factor (TNF)alpha and TNF receptors in viral pathogenesis. Proc Soc Exp Biol Med 2000; 223: 241-257.
24. Mohler KM, Sleath PR, Fitzner JN, et al. Protection against a lethal dose of endotoxin by an inhibitor of tumour necrosis factor processing. Nature 1994; 370: 218-220.

25. Kalinkovich A, Engelmann H, Harpaz N, et al. Elevated serum levels of soluble tumour necrosis factor receptors (sTNF-R) in patients with HIV infection. Clin Exp Immunol 1992; 89: 351-355.

26. Hornsleth A, Loland L, Larsen LB. Cytokines and chemokines in respiratory secretion and severity of disease in infants with respiratory syncytial virus (RSV) infection. J Clin Virol 2001; 21: 163-170.

27. Arnold R, Konig B, Galatti H, Werchau H, Konig W. Cytokine (IL-8, IL-6, TNF-alpha) and soluble TNF receptor-I release from human peripheral blood mononuclear cells after respiratory syncytial virus infection. Immunology 1995; 85: 364-372.

28. Langedijk JP, de Groot BL, Berendsen HJ, van Oirschot JT. Structural homology of the central conserved region of the attachment protein $G$ of respiratory syncytial virus with the fourth subdomain of 55-kDa tumor necrosis factor receptor. Virology 1998; 243: 293-302. 